\title{
DE LA PREOCUPACIÓN POR EL OTRO A SENTIRSE PARTE DE LA HUMANIDAD. IDENTIDAD Y VALORES EN LA EDUCACIÓN
}

\author{
Guadalupe Poujol Galván \\ Universidad Pedagógica Nacional en Morelos, México
}

\section{INTRODUCCIÓN}

Si partimos de la visión de la identidad moral como producto de la interacción entre las condiciones objetivas y la subjetividad de los individuos: ¿Qué modelos de identificación predominan en la época que nos está tocando vivir?, ¿Qué pautas de comportamiento social, están ahí, disponibles para niños y jóvenes? A nivel mundial, desdeñando los acuerdos que se han construido sobre la memoria del sufrimiento humano derivado de las guerras y la barbarie, destaca el uso de la fuerza por parte de los países con mayor poderío, para someter a los países más débiles y favorecer así su explotación económica. En estos procesos de violencia extrema, los negocios están por encima de la vida humana, de la dignidad, de la cultura y de la historia de los pueblos, de la esperanza, del medio ambiente.

Para Attali (1993:17) el dinero, el mercado y el capitalismo son conceptos indisociables, pues imponen un modo de gestión de la violencia, eficaz y universal. En este modelo la víctima propiciatoria es el que se encuentra privado del dinero y que amenaza el orden discutiendo su distribución.

En la visión de Giddens (1995:245) en un mundo en el que prevalece la desigualdad, la emancipación es la condición para que surja un programa de política para la vida. Este programa exigiría encarar dilemas morales específicos y plantear cuestiones existenciales que la modernidad ha excluido de sus instituciones.

En las circunstancias mundiales, en las que la modernidad quiebra el marco protector de la pequeña comunidad y de la tradición, sustituyéndolas por organizaciones más amplias e impersonales, Giddens plantea que el yo se ve alterado y por tanto deberá ser explorado y construido como parte de un proceso de vinculación entre el cambio personal y social.

En relación con la alteración del yo por las condiciones sociales imperantes, Touraine (1997:335) advierte que las encuestas sobre la juventud muestran que, la familia prepara a la nueva generación con medios cada vez más restringidos para el ejercicio de responsabilidades sociales y la autonomía personal. Para este autor la formación de los jóvenes es más y más caótica, como si un individuo estuviera habitado por muchos personajes. Esto provoca una experiencia de desgarramiento personal de pérdida de la identidad. El sufrimiento individual es la principal fuerza de resistencia al desgarramiento del mundo modernizado.

En Latinoamérica, las políticas económicas que resultan de la obediencia ciega por parte de la mayoría de los gobiernos a los dictados del mercado, las alianzas entre los grupos de poder económico con 
los grupos de poder político han dado como resultado la exclusión social de más de la mitad de las familias latinoamericanas y la devastación del ambiente. En la región, se desmantelan los sistemas de salud y de educación pública. Las condiciones del empleo, cuando lo hay, son más y más precarias; por ello, las familias se ven obligadas a emigrar buscando su subsistencia. El conjunto de todas estas condiciones adversas desgarran el tejido social y generan la desesperanza.

Tedesco (1997:81) considera que uno de los problemas centrales en la formación del ciudadano es el "déficit de socialización" ya que los agentes tradicionales de la socialización, como la familia, han sido sustituidos por los medios masivos y en particular por la televisión.

En Sinaloa, México, en un estudio realizado por Zúñiga, González y Torres (2001), estos autores encontraron que entre las cualidades más admiradas y deseadas por profesores, alumnos y padres de familia, figuraban:

Adquirir más paciencia y respeto, argumentado, en el primer caso, que para alcanzarla es indispensable tener tranquilidad, compasión, serenidad, control y relajamiento. En el segundo caso, se necesita seguir buenos ejemplos, respetar a los demás, respetarse a sí mismo y no criticar a quienes nos rodean.

Otras categorías de valores que exploró este estudio se refieren a los valores finales. Los alumnos desean tener un mundo en paz, además de seguridad familiar. Si alumnos, maestros y padres desean más paciencia y respeto, podría ser porque no se tiene suficiente. Por otro lado, los conflictos globales y la inestabilidad en la familia parecen estar afectando de manera muy profunda a los niños y jóvenes de hoy.

Toda esta problemática penetra en la escuela, a la exigencia social por mejorar el resultado de los educandos en el aprendizaje de los contenidos escolares, las educadoras y profesores tienen que agregar la necesidad de desarrollar rápidamente estrategias para poder trabajar con un creciente número de niños con una gran diversidad de necesidades particulares, desde aquellos que presentan falta de estimulación, apatía, déficit de atención, hasta aquellos que agreden constantemente a sus compañeros. El nivel de ansiedad va en aumento en una proporción importante de los niños, dificultando así sus posibilidades de aprendizaje.

Para ilustrar esta situación, incorporamos un fragmento de las percepciones en alumnos, padres y profesores, recogidas en el estudio sobre la exploración del esquema valoral de la comunidad escolar de primaria y secundaria en Sinaloa, conducido por Zúñiga, González y Torres (2001:187). Al ser interrogadas 603 personas sobre sus estados afectivos sus respuestas fueron:

Los sentimientos más comunes entre los alumnos encuestados, según sus propias respuestas, son la preocupación, el nerviosismo y la tristeza; los profesores y los padres de familia expresan que es la preocupación.

En cuanto a la percepción en los hijos de los sentimientos de los padres estos son: el cansancio y la preocupación, en sus madres perciben cansancio y tristeza.

Los padres perciben en los hijos: preocupación, cansancio, coraje y timidez.

Sin duda existe la necesidad de movilizar nuestros recursos en conjunto, padres, docentes y alumnos y sociedad en general, para construir comunidades más solidarias y esperanzadas.

Una estrategia para estar a la altura de las necesidades de una estructura moral en los niños, es comprender como se construye ésta. Aclaramos en primer lugar qué entendemos por moral: un saber y un sentimiento (agregamos nosotros) que nos orienta para forjarnos un buen carácter que nos permita 
enfrentar la vida, con altura humana, dice Adela Cortina, (1996:16) para ser justos y felices, humanamente íntegros.

Tedesco (Ibid :88-89) nos da pauta para la educación del ciudadano. Ante el derrumbamiento de las fuentes tradicionales de identidad surge la necesidad de que la identidad sea construida. En estas pautas la confianza en sí mismo ocupa un lugar central, pues desde ahí podrá promoverse una identidad nacional que se articule en forma coherente con la apertura y el respeto hacia los otros, hacia los diferentes. Para este autor, la educación puede y debe ser recuperada para desarrollar los sentimientos de solidaridad y de cohesión frente a las tendencias destructoras de la lógica del mercado.

\section{EL INICIO: UN MUNDO BONDADOSO Y LA CREENCIA EN LA CONFIABILIDAD}

El mundo bondadoso que requiere un bebé es la presencia de una madre (sin excluir al padre) que se adapta tan bien a sus necesidades y características, porque está tan estrechamente identificada con él o ella, de modo que sabe lo que necesita en cada momento y de manera general y está dispuesta a satisfacer esas necesidades en la medida en que se lo permitan sus capacidades humanas. Esto último es importante, pues las necesidades deben satisfacerse considerando la vida de la madre tanto como la del bebé

Este "ser cuidado lo suficientemente bien" genera en el infante una creencia en la confiabilidad, a lo cual puede añadirse una percepción de la madre, el padre, la abuela o la niñera. En un niño que inicia su vida de este modo, a continuación puede surgir naturalmente la idea de la bondad y de un progenitor confiable y personal. Winnicott (1993: 121)

La comunicación sutil y vitalmente importante entre la madre y el infante es anterior a la etapa en que es posible la comunicación verbal, por lo que el niño debe experimentar como bueno y confiable al mundo que lo rodea, pues la educación moral no sustituye al amor.

En la etapa temprana el infante reacciona a cada falla de la confiabilidad y por tanto la conoce y la registra, constantes fallas de la confiabilidad del ambiente provocan la reacción del bebé, que para Winnicott (Ibid: 126) es una interrupción del "seguir siendo" del infante y una ruptura de su incipiente sí mismo.

Winnicott da la voz de alerta sobre las graves consecuencias de las fallas constantes en la atención a las necesidades del infante, pero a la vez, plantea el término de "Cuidado suficientemente bueno" pues la provisión de cuidados para el infante, nunca es perfecta, pues éste tiene que esperar para que la madre se prepare para alimentarlo y satisfacer la amplia gama de sus demandas.

Sobre la base de un cuidado amoroso, desde el principio de la vida, los bebés pueden aprender que la satisfacción instantánea de sus necesidades no es algo que pueda esperarse en la vida cotidiana.

El tipo de interacción entre el bebé y sus padres que puede propiciar desde esta etapa la construcción de emociones, sensaciones, y más tarde intenciones y pensamientos que le posibiliten la preocupación por el otro, es aquella que satisface sus necesidades individuales, no sólo las que le permiten sobrevivir sino aquellas que lo enriquecen como ser humano, que pueden brindar unos padres afectuosos, entusiastas, entregados y estimulantes en una relación que aporta seguridad e intimidad y que poco a poco va estimulando los gestos y actitudes de reciprocidad en el bebé.

Coles (1998: 127) describe así la reciprocidad moral: 
Un bebé ha aprendido a amar en el mismo momento en que ha sido amado, a recompensar con esfuerzo a los que han hecho un esfuerzo por él, a aceptar y a complacer a aquellos que le han aceptado y complacido. Esta reciprocidad de sentimientos y de conducta, esta conexión clara, al mismo tiempo que ensancha y amplía a todos los concernidos, es una expresión temprana de un respeto compartido, de una reciprocidad de mirada, una reciprocidad moral.

Estrechamente vinculado al sentimiento de preocupación por el otro, el bebé construye la capacidad de empatía y de respeto por los demás. Según estudios de Hoffman y Trevarthen (1999:58) los bebés pueden sentir empatía tan pronto como reconocen la existencia de otros, en algunos casos en las primeras semanas de nacimiento. Según estos investigadores, otras emociones morales que hacen aparición pronto en el desarrollo son: vergüenza, culpabilidad e indignación. Se les llama emociones morales porque ayudan a los infantes a reaccionar considerando a los otros. Según hallazgos de estos autores, los niños, en diferentes culturas, empiezan su vida con sentimientos de preocupación por las personas cercanas y reacciones adversas hacia lo inhumano o lo injusto.

Las posibles actitudes ante la conducta agresiva se aprenden antes de que el niño pueda pronunciar la primera palabra de enojo. En sus interacciones con el bebé los padres están modelando su actitud ante la agresividad, y el bebé percibe lo que esperan sus padres en torno a su propia conducta agresiva.

Si de lo que se trata es de que los niños lleguen al autocontrol de sentimientos que pueden llevarlos a agredir a otros, desde los primeros intercambios preverbales, es necesario que los padres modelen la posibilidad de manejar sus impulsos y sentimientos agresivos. El enojo, el odio, la rabia, la indignación existen, no podemos ignorarlos, pero como adultos debemos ser concientes de éstos, para manejarlos; de modo que evitemos, sin más, actuar bajo su influencia.

Otro elemento fundamental en la interacción del bebé con sus padres, para la construcción de su personalidad moral, son las expectativas que expresan éstos últimos. Los gestos y actitudes como expresión de las expectativas de los padres constituyen la primera guía moral para los bebés. Las expectativas parten de la consideración de lo que está bien o de lo que está equivocado. Estas expectativas configuran el nivel más profundo de la mente en desarrollo, antes que las palabras o incluso que las imágenes visuales. Greenspan (1997:112)

Cada logro en el desarrollo de los niños, es una herramienta más para su personalidad moral. Al segundo y al tercer año de vida, con la aparición del lenguaje y el desarrollo del control muscular, aumentan las posibilidades para una educación moral explícita.

Los padres y madres tenemos que poner límites a nuestros hijos durante los primeros meses de su vida, y también ponernos nuestros propios límites, si bien un niño muy pequeño no entiende el sentido de cada una de las palabras que se le dicen, observa los gestos que las acompañan, un no dicho con firmeza (no enojo) es mejor, si va acompañado de una explicación o una conducta alternativa. Si no nos exigimos a nosotros mismos el decir no o el decir si, interferir o intervenir cuando suceden las cosas podemos crear confusión en los niños.

Sobre una base de confianza, los padres deben estar dispuestos a contrarrestar el lado egoísta e impulsivo del niño, ayudarle a aprender a aceptar el no, a entender el sí, a comprender y a responder a la diferencia en las dos palabras y lo que cada una quiere decir. En un clima de afecto, es necesario enseñar a 
los más pequeños que los demás cuentan, estimular la reciprocidad del amor, la actitud atenta de alguien que ofrece el bien, enseñar a dar y a recibir.

\section{LOS AÑOS PREESCOLARES}

Los niños y niñas que en un principio experimentan pasivamente alegría, afecto y seguridad al ser querido y cuidado, rápidamente son capaces de extender estos sentimientos a unos padres queridos, a otras personas de la familia y poco a poco a compañeros y profesores. "El sentimiento de ser atendido y de atender a los demás constituirá, finalmente la base de la empatía" Greenspan ( 1997:145)

Los sentimientos de los niños evolucionan y se vuelven más complejos con las nuevas adquisiciones intelectuales, sociales y culturales. La empatía auténtica -la capacidad de ponerse uno mismo en el lugar de los demás y de sentir preocupación por esa persona, pensando como se sentiría uno en su circunstancia- requiere de una organización psicológica más evolucionada, que desarrollan los niños al final de la etapa preescolar, y escolar cuando son capaces de crear dos mundos interiores diferenciados: uno que reacciona ante los vaivenes cotidianos de las relaciones entre iguales, y otro que comienza a desarrollar un sentido estable de la identidad.

Como expusimos antes, la empatía en la etapa preescolar no se adquiere con discursos o mensajes en carteles o en el pizarrón, aprendemos la conducta solidaria y humanitaria no de los que se nos dice, sino de cómo se nos trata.

En esta etapa, es importante diferenciar la ternura y la sensibilidad hacia los demás de la adquisición de complejas habilidades sociales que implican asumir las intenciones de otras personas, comprender sus sentimientos e incluso comportarse de forma prosocial o altruista. Esto implica que la construcción de los sentimientos propicios a la moralidad tiene que ir de la mano con el desarrollo de habilidades intelectuales y sociales.

El componente clave que determina cómo un individuo utiliza estas habilidades radica, en su sentido humanitario y de entrega, basado en la experiencia emocional.

Cuando el niño pasa de la etapa preverbal a la fase ideativa, se enriquecen su visión de sus propias intenciones y sus expectativas hacia los demás. Es capaz de evocar mentalmente la imagen de otras personas y de comprender sentimientos propios y ajenos. Esto implica un escalón más en la construcción de su personalidad moral.

Ante sus nuevas capacidades de identificar como propios los sentimientos y las intenciones, los niños necesitan cierto grado de ayuda en el control de su codicia y su rabia, tan arraigados en la condición humana como el amor y la ternura. Un niño que carece de una estructura y unos límites adecuados desarrolla una mala autoimagen al no sentirse seguro en el manejo de sus sentimientos. Es importante que se le ayude a los niños pequeños a prevenir sus reacciones agresivas para que cuando se vuelvan más verbales puedan colaborar.

En los niños preescolares es muy importante darle un gran valor a la experiencia y a la flexibilidad emocional para el desarrollo de su sensibilidad moral, que es la base de identidad moral. La educación en esta etapa debe ir orientada a propiciar la capacidad de relacionar emociones e ideas, reflexionar sobre sus 
ideas y finalmente construir un mundo interior de valores estables que permitan enfrentar las experiencias de un mundo cambiante.

En este punto, aclararemos qué estamos entendiendo por valores, retomaremos un concepto muy comprensible de Santiago Zúñiga, Andrés González y Pedro Torres (2003:166) "...son aquellos pensamientos o ideas que las personas creemos firmemente que es lo deseable o lo bueno para todos". Existe una estrecha interacción entre los valores y las motivaciones, los comportamientos, las normas, los propósitos personales, la actuación ante los conflictos y las visiones del mundo y de la sociedad que configuran nuestra manera de pensar y de actuar.

En la construcción de los valores la conducta exterior que no tiene un fundamento en el pensamiento, la decisión, la libertad y la consideración por otros se pierde, pues los niños no hacen suyos esos hábitos.

Un ambiente familiar y escolar en el que los adultos se consideren acabados, no es favorable a los valores. Una educadora que no ha reflexionado en el proceso en el que ha construido sus valores, tomando distancia de aquellos valores que le han sido impuestos, que no identifica una forma deseada de ser, y que no intenta superar los obstáculos que le impiden mejorar, difícilmente podrá brindarle a sus alumnos y alumnas la ayuda pedagógica para formarse conforme a los valores.

El procedimiento central de la formación de la educadora es la reflexión. Algunas de las interrogantes que pueden orientar esta reflexión son: ¿Qué tipo de persona quiero ser?, ¿mi conducta me ayuda para alcanzar el tipo de persona que quiero ser?, ¿qué debo hacer para llegar a ser como quiero ser?

Además de la formación de los docentes, el diálogo es una herramienta fundamental para su labor en el aula. Algunas condiciones para generar un diálogo que propicie valores son:

Partir del valor de la persona, particularmente de aquellos niños que nos provocan rechazo, no discriminar, trabajar la aceptación de cada niño y niña. Al poner límites, utilizar palabras que no lastimen a su autoestima, ayudarlos a distinguir las conductas inadecuadas y a reflexionar sobre ellas.

El logro más significativo del desarrollo de los niños en esta etapa para la construcción de su personalidad moral es el descentramiento, que es la capacidad para tomar en cuenta el punto de vista de los otros que le rodean. Sabemos con el apoyo de Kohlberg (1992:112) que el pensamiento de los niños en esta etapa es egocéntrico y la tarea de desarrollo en esta fase es apoyarlos para que poco a poco se vayan descentrando.

Los niños en esta etapa han desarrollado ya su capacidad de representación, es decir de construirse imágenes mentales de las personas y de las situaciones sociales en relación con sus experiencias y el mundo que les rodea. Esta capacidad, junto con el sentimiento de seguridad y de preocupación por los otros, constituyen la base para llegar a construir el descentramiento en los niños. Las actividades que pueden favorecer el descentramiento en los niños, son aquellas en las que se representan situaciones, de preferencia de conflictos morales de la vida cotidiana, por medio del teatro guiñol, de títeres, de imágenes, de cuentos, de expresión plástica y toda aquella actividad que le permita enriquecer su imaginario moral para hacerse conciente de las relaciones de causa y efecto entre lo que siente, piensa y hace; identificando la relación con los pensamientos, sentimientos y acciones de otros, para que sea capaz de tomarlos en cuenta al orientar su conducta. 
Un eje fundamental para fomentar el descentramiento, aunque parezca paradójico es el conocimiento de sí mismo por parte de niñas y niños, desde lo más evidente que es su cuerpo hasta lo menos evidente que son sus ideas y sentimientos, para ello, es importante que usen las palabras y las imágenes para identificar sus sentimientos, y empezar a pensar en su conducta.

Si en las aulas se fomenta la capacidad de exploración en todas las ramas del saber y la expresión humana, en un clima de libertad y respeto por el derecho de todos y cada uno, si hay espacio para la curiosidad y el placer, si se promueve un clima de cooperación en el que la palabra cobra un gran valor para resolver las diferencias y un sentimiento de gusto por pertenecer a un grupo, estaremos promoviendo al mismo tiempo la creatividad y la sensibilidad moral.

\section{LA ETAPA ESCOLAR}

Esta es la edad en la que se fortalece la conciencia y se construye el carácter de los niños. A ello contribuyen sus recién ganadas habilidades cognoscitivas, sociales, el lenguaje y destrezas motoras. Este es también el período de crecimiento de la imaginación moral, que se alimenta por la disponibilidad y la buena voluntad de los niños para ponerse en el lugar de los demás, lo que favorece poco a poco el descentramiento.

Podemos pensar en la conciencia, con Coles (ibid: 141), como:

La voz dentro de nosotros que ha oído realmente las voces de los demás, a veces nos habla a murmullos a veces nos grita, diciéndonos los que debemos hacer y lo que no, guiándonos en nuestra forma de pensar y actuar.

La cultura de padres y maestros y la manera en la que éstos se han apropiado de ella es el trasfondo de las experiencias que comparten con los niños. Es por ello importante cuestionarse como adultos qué tomamos de la cultura y que criticamos de ella. Es necesario clarificar nuestros valores cuando hablamos con los niños de lo que valoramos y observar la coherencia con nuestra conducta pues los niños están atentos a ella.

En esta etapa se avanza en la construcción de la estructura fundamental de la personalidad moral de los niños: la identidad moral. En niños mayores los ideales tienen una influencia creciente en su conducta conforme maduran. Damon $(1999,56)$ Ese proceso no es automático, pues una persona debe adoptar sus ideales como una parte central de su identidad.

Para Damon ( 1999:72) la identidad moral es “... el uso personal de principios morales para definirse a sí mismo". La identidad moral no determina únicamente lo que la persona considera el camino correcto sino además porqué toma esa decisión.

¿De qué manera se adquiere la identidad moral?. Es un proceso que se construye de muchas maneras, algunas de ellas son: retroalimentación de otros, observación de las acciones de otros que inspiran, reflexiones de la propia experiencia, influencia cultural como la familia, la escuela, las instituciones religiosas.

En cuanto a las estrategias para favorecer la conciencia moral en los niños mayores, al igual que con los niños más pequeños, la base son las relaciones que se establecen en la comunidad escolar. La interacción de los educadores con los escolares debe partir de un genuino interés por su bienestar y las experiencias de aprendizaje tienen que abarcar todas las áreas de su desarrollo, la reflexión y el lenguaje y 
la diversidad de experiencias, son fundamentales en este proceso. En un estudio de seguimiento, Damon (Op.Cit:61) y colaboradores confirmaron que el debate entre pares elevaba su conciencia sobre los derechos de otros. Los chicos que participaron activamente en el debate, expresando su opinión y escuchando el punto de vista de otros, se beneficiaron más.

Un aspecto que es necesario tener en cuenta en esta etapa es que tiene que existir una congruencia entre lo que esperan los padres y la escuela de los alumnos, para que los esfuerzos por fomentar los valores tengan efecto. En un estudio reportado por Damon (lbid:78) se encontraron altos grados de conducta cooperativa y bajos niveles de conducta antisocial entre los jóvenes de las comunidades donde había un consenso en expectativas para los jóvenes. Por ejemplo en escuelas donde están de acuerdo en que la honestidad es un valor fundamental, los maestros no toleran que los alumnos copien, los padres desalientan la mentira, los entrenadores deportivos no permiten que se violen las reglas.

En esta experiencia se destaca el valor de las normas compartidas en una comunidad escolar para la formación de las nuevas generaciones, pues las normas impuestas, que no cobran significado, no podrán ser internalizadas por los alumnos. De la revisión hecha en relación con las propuestas de los autores para promover la construcción de la identidad moral, dos de ellas nos parecen centrales: la comunidad justa (Kohlberg) y la pedagogía del cuidado.

Promover una comunidad justa en una escuela implica que tanto profesores como alumnos y directivos decidan transformar el currículo oculto, (las relaciones de poder, la manipulación, la discriminación, el pensamiento único) en currículo de justicia, en el que los derechos de los alumnos y docentes son tomados en serio y el valor de justicia y equidad tienen prioridad; las normas que surgen de la participación de todos los implicados, se van colectivizando paulatinamente. El tipo de normas que promueven una comunidad justa prohíbe acciones que infrinjan la dignidad de los otros y provee estándares de evaluación para determinar si la aplicación de normas, reglas, formas de gobierno y disciplina son justas.

Un elemento que complementa la justicia en una comunidad, es el cuidado. Conviene aquí que distingamos entre justicia y cuidado. El cuidado viene de que la persona sea consciente de la propia relación con los otros y de que en esa relación exista un sentido de responsabilidad por el bienestar de otros. La justicia viene de la conciencia de que el otro es un individuo con derechos, según Power y Makogon (1995:3)

Para Power y colaboradores, el cuidado es una característica del individuo y del grupo como un todo. El cuidado en el grupo implica que todos sus miembros se interesan por los otros y tratan de mejorar la calidad de su vida común.

En la pedagogía del cuidado de Noddings (1992:113) la idea central es que el cuidado debe entenderse como una actividad relacional. En la relación de cuidado hay que distinguir al que lo da, del que lo recibe, ambos deben contribuir a la relación.

La primera cualidad del que cuida es un experiencia de "sentir con" el otro. El cuidado va más allá de ponerse en el lugar del otro, implica una forma más compleja de reciprocidad. Este proceso no es exclusivamente emocional sino también intelectual. Otra cualidad de la relación de cuidado es que se intercambian los roles del que cuida y del que es cuidado. 
La pregunta que surge ahora es cómo pueden los docentes ayudar a sus alumnos a cuidar y a ser cuidados, en el modelo de la pedagogía del cuidado de Noddings hay cuatro componentes: el modelado, el diálogo, la práctica y la confirmación.

En el primer componente de este enfoque: el modelado a los alumnos, se les muestra como cuidar, por parte de los maestros y los padres y otros adultos. Los alumnos no aprenden a cuidarse y a cuidar a otros por lo que se les dice, aprenden a cuidar con el ejemplo, en el contexto de relaciones de cuidado. El modelado es importante pero los docentes deben estar atentos a que su función como modeladores de cuidado no los distraiga de su función principal como dadores de cuidado.

El diálogo que puede favorecer una relación de cuidado mutuo, segundo componente de esta pedagogía, no es sólo conversación, sino una forma de lograr el entendimiento, la comprensión, el aprecio o la empatía. El diálogo permite a quien cuida hablar de lo que trata de modelar, tomando en cuenta lo que piensa y siente quien recibe el cuidado.

El tercer componente de la educación moral desde la perspectiva del cuidado es la práctica. Aprender como cuidar a otros requiere práctica, perseverancia, de la misma manera como uno aprende nuevas habilidades y actitudes. Una forma en la que puede practicarse el cuidado mutuo es en el aprendizaje cooperativo pues es una forma de involucrase en relaciones genuinas de cuidado. Los proyectos escolares de servicio a la comunidad pueden ser una forma adicional de practicar el cuidado.

El cuarto componente es la confirmación, que es una forma de afirmar y estimular lo mejor de los otros, animando en la persona cuidada la construcción de un "mejor sí mismo". La confirmación es una respuesta genuina a los otros, en el contexto de sus circunstancias específicas.

\section{LA ADOLESCENCIA Y LA CONCIENCIA MORAL}

La adolescencia es una etapa clave para el desarrollo moral, precisamente por que como ser humano cuenta ya con las herramientas necesarias para construir e interiorizar sus propios valores. El desarrollo de la independencia es una necesidad, un camino y una meta para la construcción del individuo.

El docente que desee ser escuchado por los adolescentes debe abandonar su posición de juez y dejar en claro que los adultos somos personas como ellos, vulnerables, que nos equivocarnos, que tenemos que tolerar la incertidumbre de la vida, que hemos experimentado cosas semejantes a las que viven y que deseamos comunicarnos con ellos. Al mismo tiempo los adolescentes necesitan a un adulto que si bien reconoce su vulnerabilidad como ser humano es capaz de transmitirle orientación, seguridad, esperanza y alegría de vivir.

Las actitudes, problemas, logros, dificultades y los traumas anteriores se vuelven significativos cuando los jóvenes se aferran desesperadamente a lo que han conseguido y a lo que han sido, al mismo tiempo que se aventuran en un nuevo y a menudo, terrible territorio. No es de extrañar que los asuntos del bien y del mal, la esencia misma del pensamiento moral, puedan cobrar un poderoso sentido en este período, a menudo expresado indirectamente a través de preguntas directas y de rechazos de lo convencional, como forma de obtener para sí mismo algo "mejor". Coles (Ibid:200)

Precisamente cuando los jóvenes están estrenando su capacidad para observarse a sí mismos, dándose cuenta desde afuera cómo piensan y cómo actúan, cuando son objetos y sujetos de su reflexión, la sociedad los orilla a tomar decisiones trascendentales para su vida. Los adolescentes tienen que usar sus nuevas capacidades para evaluar algunos asuntos morales. En la identidad moral de los adolescentes que 
se comprometen con una causa colectiva encontramos que sus preocupaciones sobre el sufrimiento humano son centrales en la manera en la que ellos piensan sobre sí mismos y en sus metas y de ésta manera sienten una responsabilidad para actuar aún a un costo personal.

Muchos adolescentes están concientes de los problemas morales, pero para ellos estos asuntos parecen remotos de sus propias vidas. El contexto individualista en el que estos se desenvuelven tiene una influencia en la indiferencia de algunos adolescentes a los asuntos que competen al conjunto de la sociedad. Esto es lo que encontró en su estudio García Díaz ( 2001:263) sobre los valores del educando adolescente. La población de estudio estuvo conformada por adolescentes de cuatro escuelas oficiales de la zona metropolitana de la Ciudad de México, del nivel medio superior, de diferentes grados escolares y de ambos sexos. La autora analiza así los resultados obtenidos en su investigación:

Con respecto a la orientación del valor, hubo catorce $(74 \%)$ valores de orientación individual y cinco $(26 \%)$ de orientación colectivista, lo que implica que el adolescente como el niño, sigue siendo egocéntrico, piensa más en él que en los demás. No obstante, hay que considerar también que se encuentra en una sociedad más individualista que colectivista.

Como expusimos antes, la preocupación por el otro se desarrolla en la infancia y si el adolescente no ha tenido la oportunidad de sentir que forma parte de la humanidad, difícilmente sentirá interés por algo que esté fuera del círculo concreto en el que se desenvuelve. Si bien la información sobre los acontecimientos globales y locales, puede propiciar su interés y preocupación, el conocimiento moral no es suficiente para motivar la acción moral.

Una estrategia valiosa para propiciar la construcción de la identidad moral en los adolescentes es el relato, pues de acuerdo con Cyrulnik (2003: 134) la creación de una historia es necesaria para la supervivencia psíquica, en una etapa en la que las certezas se derrumban. Las narraciones íntimas o culturales pueden construir, en el mundo psíquico, el equivalente a un vínculo protector. Todos estamos obligados a recorrer este proceso para construir nuestra identidad. La ensoñación da forma, mediante imágenes, al regreso de la esperanza. Del imaginario se extraen algunas razones para transformar la realidad y esto constituye un mecanismo de defensa ante la inestabilidad que es la vivencia que acompaña a la adolescencia.

El proceso de identidad en esta etapa se vuelve más complejo, la educación moral puede ayudar a que en ese espacio íntimo en el que el adolescente se representa a sí mismo y puede ya juzgarse en sus pensamientos y acciones; incorpore el sentido de la responsabilidad, que desde el punto de vista moral implica cuidarse uno mismo y cuidar a los otros, tomar decisiones en el horizonte de un proyecto personal en el que los otros figuran, trabajar para mejorar la condición humana. Para Ricoeur (1996:260), el sujeto debe asumir responsabilidad de sus actos, de sus acciones y consecuencias, de su historia, de sus palabras, de su futuro.

La tarea de crear las condiciones para que niños y jóvenes construyan su identidad moral, y que en diálogo con ella realicen valores, es como vemos, compleja, si a ello agregamos que los docentes se desempeñan en un medio competitivo, en el que los profesores y profesoras tienen escasas oportunidades, dada la saturación de expectativas y actividades, de reflexionar en que estado se encuentra su propia personalidad moral.

Hemos analizado en este trabajo que si se desea por parte de los niños una verdadera interiorización y apropiación de los valores en su identidad moral, es necesario brindar a los docentes las 
oportunidades para tomar distancia de sus actitudes, analizarlas y propiciar el desarrollo de las competencias necesarias para que puedan hacer cambios, según su propia idea de lo que es deseable como docente. Es necesario que se atiendan sus condiciones y sus derechos para que éstos puedan a su vez promover los derechos de sus alumnos.

\section{REFERENCIAS}

ATtALI, Jacques. Milenio. Barcelona Seix Barral, 1993

COLES, Robert. La inteligencia moral del niño y del adolescente. Barcelona Kairós, 1997

CORTINA, Adela. El quehacer ético. Guía para la educación. Madrid, Santillana, 1996

DAmON, William. Scientific American. Agosto 1999, Volumen 281, Número 2, New York. 1999

GARCíA, Diana. "Estudio sobre los valores del educando adolescente de la ciudad de México: la voz del propio joven". En HIRSH, Ana (compiladora), Educación y valores. México, Gernika, 2001

GIDDENS, Anthony Modernidad e identidad del yo. El yo y la sociedad en la época contemporánea. Barcelona, Península, 1995

GREENSPAN, S. Y Benderly, B. El crecimiento de la mente y los ambiguos orígenes de la inteligencia. Barcelona, Paidós, 1997

Noddings, N. The challenge to care in schools: An alternative approach to education. New York: Teachers College Press, 1992

KOHLBERG, Laurence. Psicología del desarrollo moral. Bilbao, Desclée de Brower, 1992

POWER, C. et al. Aproach to moral education. New York, Columbia University Press, 1992

Tedesco, Juan Carlos "La educación y los nuevos desafíos de la formación del Ciudadano" en Nueva sociedad. No 146, nov-dic. Caracas, E. Texto, 1996

TOURAINE, Alain. ¿Podremos vivir juntos?, Buenos Aires, FCE, 1997

WINNICOTT, Donald. Los procesos de maduración y el ambiente facilitador. Argentina, Paidós, 1993. 


\title{
Contactar
}

Revista lberoamericana de Educación

\author{
Principal OEI
}

